\title{
Purificación y amplificación de ADN genómico en escamas de la serpiente Bothrops atrox “jergón” (Ofidia: Viperidae)
}

\section{Genomic DNA purification and amplification from scales to snake Bothrops atrox "lancehead" (Ofidia: Viperidae)}

\author{
Rommel Rojas ${ }^{1}$, Roberson Ramirez ${ }^{1}$, Marianela Cobos ${ }^{1}$ y Juan Castro ${ }^{1,2}$ \\ 1 Centro de Investigaciones de Recursos Naturales-CIRNA \\ 2 Universidad Nacional de la Amazonia Peruana-UNAP. Apartado postal 496S Facultad de Ciencias \\ Biológicas.
}

\section{RESUMEN}

Los estudios moleculares exigen la creación de nuevos protocolos que permitan obtener un ADN de alta calidad en la mayor cantidad de especies posibles y garantizar el conocimiento de la diversidad genética, por tal motivo el objetivo del presente trabajo fue purificar y amplificar de ADN genómico de las escamas de la serpiente Bothrops atrox "jergón". Las escamas fueron recolectadas en el campo utilizando la técnica de revelamiento por encuentros casuales [1], para la purificación del ADN genómico se modificó el protocolo de [2], verificándose su pureza por el método electroforético utilizando agarosa $2 \%$ y su calidad y concentración por el método espectrofotométrico, la amplificación fue realizada por la reacción en cadena de polimerasaPCR utilizando iniciadores aleatorios. Los resultados muestran la obtención de ADN en excelente estado con un alto ratio de calidad (2) y concentración $(585.85 \mu \mathrm{g} / \mathrm{mL})$, asimismo se logró la amplificación del ADN, demostrándose que el protocolo utilizado es útil para estudios moleculares y genéticos. Se concluye mencionado que el método empleado es efectivo para obtener ADN de buena calidad en escamas de serpientes.

Descriptores: Serpiente, escama, $A D N$, reacción en cadena de polimerasa-PCR.

\begin{abstract}
Molecular research demand the creation of new protocols and permit the obtain a high quality DNA in the most quantity of species and know the genetic diversity, for that objective of the present research was obtained the purification and amplification of scales DNA in the snake Bothrops atrox. the scales were recollected in the field using the visual encounter survey [5] The For the purification of the DNA was modification the protocol [4], the DNA purity was verifiable for the electrophoretic method and it quality and concentration for spectrophotometry, the amplification was carried for Polymerase chain reaction-PCR using random primers. The results show the successful DNA purification, showing an acceptable quality ratio (2) and concentration $(585.85 \mu \mathrm{g} / \mathrm{mL})$, at the same time was made the amplification of DNA for PCR. We conclude indicating the useful of this technique for the purification of high quality DNA from snake's scales for molecular and genetic research.
\end{abstract}

Keywords: snake, scale, DNA, polymerase chain reaction-PCR

\section{INTRODUCCIÓN}

Los análisis moleculares utilizando ADN genómico han revolucionado los estudios de sistemática, ecología, evolución y genética, siendo utilizados para solucionar problemas de distinción entre individuos, poblaciones, especies y taxas cercanas, y para evaluar las relaciones filogenéticas en plantas, animales y microorganismos [1].

Mientras estos análisis han provisto de métodos extremadamente útiles, la recolección de muestras para estos estudios en serpientes, a menudo involucran técnicas que agreden al animal tal como 
la extracción de sangre o tejido [2], y muchas veces su innecesario sacrificio, especialmente de aquellos que están en peligro.

Existen estudios de obtención de ADN utilizando sangre [3] y mudas [4] de serpientes, sin embargo, la extracción de sangre puede causas daños al animal y muchas veces las mudas son muy difíciles de encontrar e identificar en el campo, siendo las escamas una muestra efectiva y que produce bajos niveles de daños y estrés al animal.

Existen pocos estudios que nos permitan obtener un ADN de alta calidad y su amplificación para investigaciones moleculares en serpientes, los cuales se apliquen a mejorar el conocimiento de estas especies a nivel genético.

En este sentido el presente trabajo tuvo como objetivo purificar y amplificar el ADN en escamas de la serpiente Bothrops atrox "jergón".

\section{EXPERIMENTAL}

\section{Área de Estudio}

Se realizó en el Laboratorio de Biotecnología del Centro de Investigaciones de Recursos Naturales de la Amazonía (CIRNA) de la Universidad Nacional de la Amazonía Peruana; situada en el AA.HH. Nuevo San Lorenzo. Psje. Los paujiles S/N.

\section{Muestreos Herpetológicos}

Las muestras fueron recolectadas a través de muestreos herpetológicos en el campo utilizando la técnica del revelamiento por encuentros visuales (V.E.S) [1] en 3 lugares de la ciudad de lquitos: la comunidad de Moena caño con coordenadas geográficas de: Latitud sur $3^{\circ} 46^{\prime} 22.53^{\prime \prime} y$ latitud oeste $73^{\circ} 14^{\prime} 27^{\prime \prime}$, comunidad de Isla lquitos cuya ubicación geográfica es: latitud sur: $3^{\circ} 43^{\prime} 58.83^{\prime \prime}$ latitud oeste: $3^{\circ} 49^{\prime} 8^{\prime \prime}$, comunidad de Ninarumhi, cuya ubicación geográfica es de: latitud sur: $3^{\circ}$ $48^{\circ} 04.76^{\prime \prime}$ latitud oeste: $75^{\circ} 25^{\prime} 40^{\prime \prime}$

\section{Recolección de Muestras}

Las escamas fueron extraídas por manipulación directa de 10 especímenes con ayuda de una tijera y pinzas estériles, colocadas en microtubos de $1.5 \mathrm{ml}$ y congeladas a $-20^{\circ} \mathrm{C}$.

\section{Purificación de ADN genómico}

Se modificó el protocolo establecido por [2] para mudas de serpientes que consistió en los siguientes pasos:

Se pesó $0.08 \mathrm{mg}$ de escamas, lavándose con abundante agua ultrapura, siendo cortadas en pequeños pedazos, seguidamente se agregó $900 \mu \mathrm{l}$ de buffer de lisis (10 mM Tris-base, $100 \mathrm{mM}$ EDTA, $2 \%$ SDS, pH 8.0) y $9 \mu \mathrm{l}$ de proteinasa $\mathrm{K}(1 \mathrm{mg} / \mathrm{ml})$, incubándose en baño María a $65^{\circ} \mathrm{C}$ durante 24 horas. Luego de ello, se dejó atemperar por 5 minutos, y colocó $300 \mu \mathrm{l}$ de Acetato de amonio 7.5M, dejándose en hielo por 15 minutos, luego se centrifugó a 15000 rpm durante 3 minutos, se separó el sobrenadante y agregó $500 \mu \mathrm{l}$ de Cloroformo alcohol isoamilico (24:1), mezclándose manualmente y centrifugando a $15000 \mathrm{rpm}$ por 3 minutos, el sobrenadante fue separado y se agregó $900 \mu \mathrm{l}$ de Isopropanol, dejándose en refrigeración por 12 horas.

Seguidamente se centrifugó a $15000 \mathrm{rpm}$ durante 15 minutos, se descartó el sobrenadante y dejo invertido por 3 minutos, luego se colocó $700 \mu l$ de etanol al $70 \%$ y desprendió el pellet manualmente, seguidamente se centrifugó a 15000 rpm por 3 minutos, descartándose el sobrenadante e invirtiendo los microtubos por 5 minutos, finalmente se agregó $80 \mu \mathrm{l}$ de buffer TE $(10 \mathrm{mM}$ tris, $0.1 \mathrm{mM}$ de EDTA) y dejó en refrigeración por 5 horas.

\section{Electroforesis de ADN genómico}

Se realizó en un gel de agarosa al $2 \%$ teñido con Bromuro de etidio, realizándose la corrida electroforética a $85 \mathrm{~V}$ durante 45 minutos.

Para la visualización del ADN se utilizó la cámara de luz ultravioleta.

\section{Espectrofotometría de ADN genómico}

Se utilizó un espectrofotómetro de luz ultravioleta (HACH; DR 4000U). Para la obtención de la calidad de ADN se aplicó la siguiente formula:

$$
\text { Abs } 260 \mathrm{~nm} / \text { Abs } 280 \mathrm{~nm}^{2}=1.8 \pm 0.2
$$

Mientras que para la concentración:

$$
\mu g / m l=A b s 260 * 50 * \text { Factor de dilucion }
$$

Las lecturas de las muestras fueron realizadas por duplicado, utilizando los promedios como datos representativos. 


\section{Amplificación de ADN genómico}

Se preparó el Master Mix, el cual estuvo compuesto por agua ultrapura, Buffer 10x, Cloruro de Magnesio $\left(\mathrm{MgCl}_{2}\right) \quad 25 \mathrm{mM}$, Primers aleatorios, desoxiribonucleotidos (dNTPs) $10 \mathrm{mM}$, Taq DNA Polimerasa $5 \mathrm{U} / \mu \mathrm{l}$ y ADN $(100 \mu \mathrm{g} / \mathrm{ml})$.

Las reacciones de amplificación se llevaron a cabo empleando un termociclador programado bajo las siguientes condiciones de temperatura: desnaturación inicial de $96^{\circ} \mathrm{C}$ por $4 \mathrm{~min}, 40$ ciclos $\left(96^{\circ} \mathrm{C}\right.$ por $30 \mathrm{~s}, 36^{\circ} \mathrm{C}$ por 30 s y $72^{\circ} \mathrm{C}$ por $1 \mathrm{~min}$ ) y una extensión final de $72^{\circ} \mathrm{C}$ por $10 \mathrm{~min}$. Los productos de amplificación fueron resueltos por electroforesis en gel de poliacrilamida al 10\%, utilizando la tinción argentina propuesta por [6].

\section{RESULTADOS Y DISCUSIÓN}

La figura 1 muestra el ADN purificado de escamas de la serpiente Bothrops atrox "jergón", observándose un ADN en buen estado de conservación, asimismo no se observa restos de ARN ni polisacáridos.

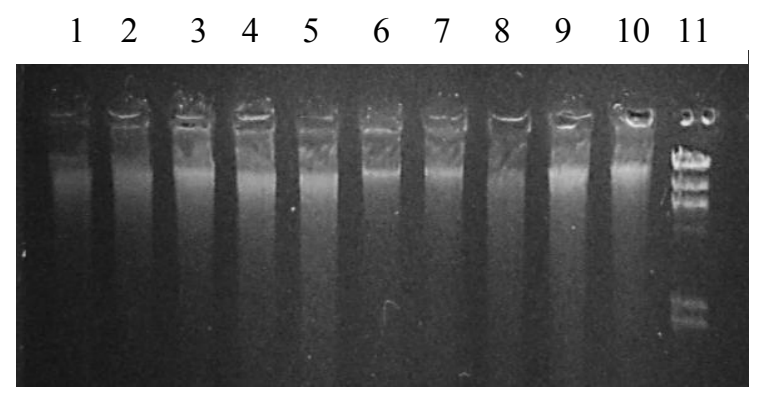

Figura 1. ADN genómico de escamas de Bothrops atrox "jergón" en gel de agarosa 2\%, línea 1-10 ADN genómico, 11 marcador de peso molecular ( $\Lambda$ Hind III, Fermentas, $0.1 \mu \mathrm{g} / \mathrm{ml}$ )

En la tabla 1 se muestra las lecturas espectrofotométricas realizadas a las muestras, observándose el alto grado de calidad y de concentración de ADN
Tabla 1. Análisis espectrofotométrico del ADN de Bothrops atrox "jergón"

\begin{tabular}{|c|c|c|c|c|c|c|}
\hline \multirow[b]{2}{*}{$\mathbf{N}^{\circ}$} & \multirow[b]{2}{*}{$\begin{array}{c}\text { Abs. } \\
280 \\
\mathrm{~nm}\end{array}$} & \multirow[b]{2}{*}{$\begin{array}{l}\text { Abs. } \\
260 \\
\mathrm{~nm}\end{array}$} & \multicolumn{2}{|c|}{ Promedio } & \multirow{2}{*}{$\begin{array}{c}\text { Ratio de } \\
\text { calidad } \\
\text { (Abs260/ } \\
\text { Abs 280) }\end{array}$} & \multirow[b]{2}{*}{$\mu \mathrm{g} / \mathrm{ml}$} \\
\hline & & & $\begin{array}{c}\text { Abs } \\
280 \\
\mathrm{~nm} \\
\end{array}$ & $\begin{array}{c}\text { Abs } \\
260 \mathrm{~nm}\end{array}$ & & \\
\hline \multirow{2}{*}{1} & 0.097 & 0.176 & \multirow{2}{*}{0.097} & \multirow{2}{*}{0.176} & \multirow{2}{*}{1.8} & \multirow{2}{*}{880} \\
\hline & 0.097 & 0.176 & & & & \\
\hline \multirow{2}{*}{2} & 0.051 & 0.102 & \multirow{2}{*}{0.051} & \multirow{2}{*}{0.102} & \multirow{2}{*}{2.0} & \multirow{2}{*}{510} \\
\hline & 0.051 & 0.102 & & & & \\
\hline \multirow{2}{*}{3} & 0.051 & 0.102 & \multirow{2}{*}{0.051} & \multirow{2}{*}{0.1015} & \multirow{2}{*}{2.0} & \multirow{2}{*}{507.5} \\
\hline & 0.051 & 0.101 & & & & \\
\hline \multirow{2}{*}{4} & 0.076 & 0.155 & \multirow{2}{*}{0.076} & \multirow{2}{*}{0.1545} & \multirow{2}{*}{2.0} & \multirow{2}{*}{772.5} \\
\hline & 0.076 & 0.154 & & & & \\
\hline \multirow{2}{*}{5} & 0.075 & 0.151 & \multirow{2}{*}{$\begin{array}{c}0.074 \\
5\end{array}$} & \multirow{2}{*}{0.151} & \multirow{2}{*}{2.0} & \multirow{2}{*}{755} \\
\hline & 0.074 & 0.151 & & & & \\
\hline \multirow{2}{*}{6} & 0.023 & 0.045 & \multirow{2}{*}{0.023} & \multirow{2}{*}{0.045} & 20 & 225 \\
\hline & 0.023 & 0.045 & & & 2.0 & $\angle \angle 0$ \\
\hline 7 & 0.036 & 0.072 & 0,36 & م70 م & 20 & 360 \\
\hline$t$ & 0.036 & 0.072 & 0.000 & 0.012 & 2.0 & 200 \\
\hline 8 & 0.059 & 0.124 & 0059 & 0124 & 21 & 620 \\
\hline 0 & 0.059 & 0.124 & 0.059 & $0.1 \angle 4$ & 2.1 & $0 \angle 0$ \\
\hline 0 & 0.073 & 0.151 & & & 1 & \\
\hline$y$ & 0.073 & 0.151 & 0.073 & 0.1512 & 2.1 & 156 \\
\hline 10 & 0.044 & 0.094 & & & & \\
\hline 10 & 0.044 & 0.095 & 0.044 & 0.0945 & 2.1 & $47<.5$ \\
\hline & & Prome & dio & & 2.0 & 585.8 \\
\hline
\end{tabular}

En la figura 2 se observa la amplificación del ADN genómico utilizando iniciadores aleatorios.

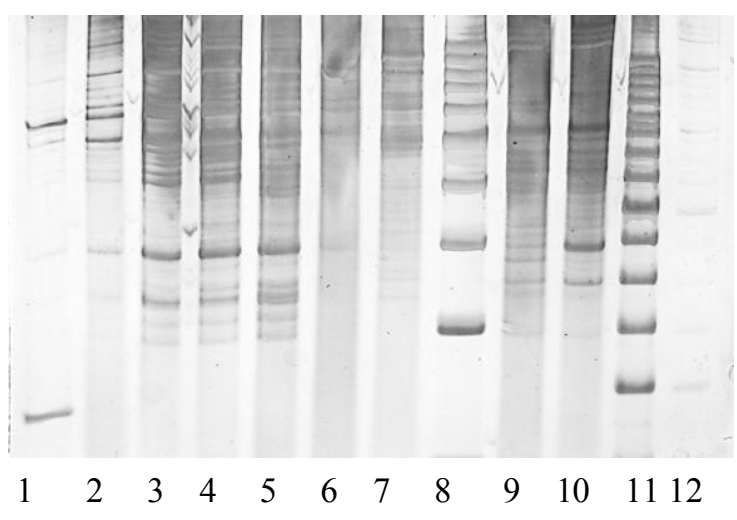

Figura 2. Amplificación del ADN genómico por la reacción en cadena de polimerasa-PCR, línea 1-7, $9,10,12$ productos de amplificación, 8, 11 marcadores de peso molecular (100 pb Ladder Plus Fermentas $0.501 \mu \mathrm{g} / \mathrm{ml}$ y $50 \mathrm{pb}$ Ladder Invitrogen $1.01 \mu \mathrm{g} / \mathrm{ml})$

La electroforesis muestra la integridad del ADN purificado por el método de [4], modificado en nuestras condiciones de trabajo, sin embargo, este método está orientado a la extracción de ADN para mudas, pero a este protocolo se le adiciona nuevos procedimientos, los cuales garantizan la obtención del ADN en buen estado en escamas de serpientes. 
La calidad y concentración de ADN observado por espectrofotometría demuestra que el $A D N$ se encuentra dentro del rango de aceptación, siendo demostrado por la amplificación mediante la reacción en cadena de polimerasa-PCR con iniciadores aleatorios. [3,7] También realizaron la amplificación con iniciadores aleatorios, en las especies de Crotalus sudamericanas y Bothrops de Brazil, utilizando para ello muestras de sangre.

[8,9] Realizaron la extracción de ADN en mudas de serpientes, sin embargo, muchos de estos trabajos se realizan con mudas frescas, obtenidas de zoológicos o centros de crías, pero en zonas tropicales existe una rápida degradación de este tipo de muestra, lo cual puede dificultar la obtención de ADN en buen estado, asimismo, obteniéndose mudas, es muy complicado la identificación de la especie, pues en muchas ocasiones algunas especies varían fenotípicamente entre individuos.

Por otro lado existen protocolos donde han utilizado sangre de serpientes [10] los cuales se realizan por punción cardiaca pero muchas veces la falta de experiencia de investigadores puede causar daños o estresarlas de manera que es muy riesgosa, de igual manera, la extracción del tejido, el método presentado, provee la purificación del ADN en muestras que no significan ningún riesgo para el animal, como son las escamas y garantiza su uso en estudios moleculares y genéticos a través de su amplificación por PCR que permita observar la variación genética utilizando las herramientas moleculares y provean una amplia gama de conocimientos.

\section{CONCLUSIONES}

Se logró la purificación y amplificación del ADN genómico en escamas de la serpiente Bothrops atrox, asimismo es importante destacar la creación de nuevos protocolos que permitan la obtención de ADN genómico útil y provean de herramientas para las investigaciones moleculares en diferentes especies de animales y plantas.

\section{AGRADECIMIENTOS}

Al Centro de Investigación de Recursos NaturalesCIRNA-UNAP.

Al proyecto "Herramientas biotecnológicas para la obtención de líneas celulares de alta rendimiento de vitamina C de Myrciaria dubia (HBK) McVaugh "camu camu" por el financiamiento realizado a la presente investigación.

\section{REFERENCIAS}

[1] M. Crump, J. Scott. Smithsonian Institution Press (1994) 84-92.

[2] J. Fretzner. Bio techniques 26(1999) 10521054.

[3] B.S. Master. Herpetology 26 (1995) 92-95.

[4] Branch. Journal of herpetology association 11(1973) 5-6.

[5] M. M. E. Duarte, A.S. Pilla, C.E. Mayer, J. Applied Electrochemistry. 33(2003)387-392

[6] B. Bassan, P. Gress. Nature protocols 2(2007) 2649-2654.

[7] F. Grazziotin, S. Echeverrigaray. Brazilian archives of biotechnology 48(2005) 359-365.

[8] J. Bricker, L. Bushar, H. Reinert, L. Gelbert. Herpetological Review 27(1996) 133.

[9] A. Clark. Herpetological Review 29(1998) 1718.

[10] N. Lopes. Universidade Catolica do Goias (2006) 1-96

E-mail: Biorojas_2358@hotmail.com 